\title{
Extreme Historical Droughts in the South-Eastern Alps - Analyses Based on Standardised Precipitation Index
}

\author{
Mihael BRENČIČ \\ Department of Geology, Natural Sciences and Engineering Faculty, \\ University of Ljubljana, Ljubljana, Slovenia; e-mail: mihael.brencic@ntf.uni-lj.si \\ Geological Survey of Slovenia, Ljubljana, Slovenia
}

\begin{abstract}
Droughts are natural phenomena affecting the environment and human activities. There are various drought definitions and quantitative indices; among them is the Standardised Precipitation Index (SPI). In the drought investigations, historical events are poorly characterised and little data are available. To decipher past drought appearances in the southeastern Alps with a focus on Slovenia, precipitation data from HISTALP data repository were taken to identify extreme drought events (SPI $\leq$ -2.00) from the second half of the 19th century to the present day. Several long-term extreme drought crises were identified in the region (between the years 1888 and 1896; after World War I, during and after World War II). After 1968, drought patterns detected with SPI changed: shorter, extreme droughts with different time patterns appeared. SPI indices of different time spans showed correlated structures in space and between each other, indicating structured relations.
\end{abstract}

Key words: drought, standardized precipitation index, drought indicator diagram, HISTALP data set, south-eastern Alps.

Ownership: Institute of Geophysics, Polish Academy of Sciences;

(C) 2016 Brenčič. This is an open access article distributed under the Creative Commons Attribution-NonCommercial-NoDerivs license,

http://creativecommons.org/licenses/by-nc-nd/3.0/. 


\section{INTRODUCTION}

Droughts are natural phenomena affecting various human activities and economic sectors; they can influence the environment and cause social hardships, and their consequences are traceable long after the amount of water in the region is re-established by precipitation. Drought events are consequences of climate variability as well as of the redistribution of water inside the hydrological cycle. In spite of their wide and sometimes unpredicted consequences, they can be listed among scientifically less understood hydrological phenomena, still stimulating various research questions and activities. Today, drought monitoring is very well developed at different spatial scales and drought events of various magnitudes are carefully followed. However, past drought events are not well documented; further in the past, there is less information available for particular drought events. Knowledge of past drought events is not just of academic importance, it is crucial for the understanding of recent drought pattern persistence, frequency of droughts and detection of trends in the spatial and time appearance of droughts. Historical droughts have been studied at various scales in different regions around the globe (Sheffield and Wood 2011). These studies are mainly focused on the period after World War II. Analyses dealing with longer time series are rare due to the lesser availability of data needed for older drought detection. Lloyd-Hughes and Saunders (2002) and Briffa et al. (2009) addressed historical droughts at the European scale, and Sousa et al. (2011) analysed historical droughts in the Mediterranean basin. Several studies have outlined historical droughts at the regional scale for various European countries or geographical regions (Brázdil et al. 2009, Gocic and Trajkovic 2014, Spraggs et al. 2015).

In this paper, drought indicators based on the Standardised Precipitation Index (SPI) developed by McKee et al. (1993, 1995) were calculated for very long-term precipitation records of nine meteorological stations in the south-eastern Alps region with a focus on Slovenia and its immediate surroundings. Data were taken from HISTALP data repository, where historical meteorological time series for the greater Alpine region are available (Auer et al. 2007, Böhm et al. 2010). Calculations were intended to decipher past appearances of droughts and their spatial and temporal patterns in the southeastern Alps region, and to provide an understanding of their influences on water scarcity in the region driven by the deficiency of precipitation.

\section{METHODS}

Drought is a complex phenomenon and several conceptual and operational definitions of it exist (Wilhite and Glantz 1985). Droughts are generally classified in five conceptual categories: meteorological, hydrological, agri- 
cultural, socio-economic (Dracup et al. 1980, Wilhite and Glantz 1985) and groundwater drought (Mishra and Singh 2010). The most easily detected drought (temporarily preceding other types of drought) is the meteorological drought, which, according to Mishra and Sing (2010) is defined "as a lack of precipitation over a region for a period of time". There are many meteorological drought indicators (Quiring 2009); among them, due to its simplicity and ease of calculation compared to others (Guttman 1998, Keyantash and Dracup 2002), the SPI has gained popularity. The SPI has been used for the examination of drought historical characteristics (Lloyd-Hughes and Saunders 2002, Kim et al. 2011), for the identification of links between drought and atmospheric conditions (Hannaford et al. 2011, Kingston et al. 2015), and to monitor the progression of a drought through space and time (Sušnik et al. 2010). The concept of the SPI can also be applied to other hydrological and meteorological parameters (Mishra and Singh 2010), and its simplicity is especially useful for historical drought studies.

The SPI was developed by McKee and colleagues for drought detection in Colorado, USA (McKee et al. 1993, 1995; Edwards 1997). Soon after its first application, the SPI gained wider usage; nowadays, it is frequently used for local or national drought monitoring (Svoboda et al. 2002) or at the global scale for the detection of drought patterns (Sheffield and Wood 2011). It is the key drought indicator, as recommended by international agencies (e.g., WMO 2006). Compared to other meteorological drought indicators, the SPI is based only on monthly precipitation totals, which, for long periods, are more easily obtained than most other meteorological parameters. At the same time, this is a weakness of the SPI, as it ignores both evapotranspiration of the climatic water balance and terrestrial stores and fluxes (Kingston et al. 2015). The only requirement for the calculation of the SPI is having a continuous precipitation time series. The SPI is defined in that it can monitor dry and wet periods over a wide spectrum of time scales: from one month and on. It is limited only regarding the length of available precipitation time series.

According to its definition (McKee et al. 1993, 1995; Edwards 1997) the SPI is a drought indicator and does not represent the entire complex situation of the drought appearance and its consequences. It defines the conditions in the atmosphere as a relative water deficit reflected in precipitation. Therefore, historical SPI values must be interpreted as an indicator of a meteorological drought and not a drought in general. It is expected that some events classified as meteorological droughts by the SPI will not be included in historical files and vice versa.

The SPI begins with building a frequency distribution from precipitation data from a location for a specified period. The determination of the probability density function is an essential step in the calculation of the SPI and 
plays an important role in the drought detection (Guttman 1999, Quiring 2009). Ergodicity of the precipitation time series and time-dependent stability of the modelling probability distribution parameters are also very important. In the literature, several distributions were tested and compared (Guttman 1999). The most common and widely applied and (built into many software applications) is the two-parameter gamma probability density function (Bobée and Ashkar 1991).

A gamma probability density function of a given frequency distribution of precipitation totals for the station of interest is fitted to the precipitation data (Edwards 1997) as:

$$
g(x)=\frac{1}{\beta^{a} \Gamma(\alpha)} x^{\alpha-1} e^{-x / \beta}
$$

where $\alpha>0$ is a shape parameter, $\beta>0$ is a scale parameter, $x$ is the precipitation amount in a time unit and $\Gamma(\alpha)$ is the Euler gamma function. Shape parameter $(\alpha)$ and the scale parameter $(\beta)$ are estimated for each time scale of interest and are calculated as:

$$
\begin{gathered}
\widehat{\alpha}=\frac{1}{4 A}\left(1+\sqrt{1+\frac{4 A}{3}}\right) \\
\beta=\frac{\bar{x}}{\widehat{\alpha}} \\
A=\ln (\bar{x})-\frac{\sum \ln (x)}{n}
\end{gathered}
$$

where $n$ is the number of observations in the time scale of interest. The cumulative probability of each observed precipitation event for the given time scale for the station of interest is then computed using the estimated shape and scale parameters.

$$
G(x)=\int_{0}^{x} g(x) d x=\frac{1}{\widehat{\beta}^{\widehat{\alpha}} \Gamma(\widehat{\alpha})} \int_{0}^{x} x^{\widehat{\alpha}-1} e^{-x / \widehat{\beta}} d x
$$

An equiprobability transformation is made from the cumulative probability of the standard, normal, random variable $(Z)$ with a mean of zero and variance of one (Abramowitz and Stegun 1972), where the SPI takes on the value of $Z$. Because a precipitation time series must be continuous, calculations of SPI also generate a continuous time series where values are defined on the entire scale of the standard, normal, random variable $Z$. Positive values of the SPI define periods of water surplus and negative values define wa- 
ter deficits that can be related to the drought periods with various magnitudes. The magnitude of a drought is estimated according to Table 1 (McKee et al. 1995).

Table 1

SPI drought categories classification (McKee et al. 1993, 1995)

\begin{tabular}{|r|l|}
\hline \multicolumn{1}{|c|}{ SPI } & Drought category \\
\hline 0 to -0.99 & Near normal \\
-1.00 to -1.49 & Moderately dry \\
-1.50 to -1.99 & Severely dry \\
$\leq-2.00$ & Extremely dry \\
\hline
\end{tabular}

The SPI can be computed for any time period in $1,2,3, \ldots, 48, \ldots$ months. The SPI for 1 and 3 months is used as an indicator of short time droughts, SPI for 6 and 12 months is an indicator of moderate droughts and for 24 and 48 months is an indicator of long droughts (McKee et al. 1995, Edwards 1997). For example, agricultural users may be interested in shorter periods, while hydrologists or water managers might be interested in SPI values for 12 or 24 or longer months (Wu et al. 2001). The SPI for a particular cumulative time period is defined as an order $i$ of SPI; for instance, the SPI for 6 months is defined as the SPI of order 6 or SPI6.

The length of a total precipitation record applied in the analysis has a significant impact on the SPI values (Mishra and Singh 2010). The application of precipitation records with different lengths can result in different SPI values for the same observation point (Mishra and Singh 2010). Bias in SPI calculated values can appear where precipitation is seasonal in nature and where zero values commonly influence the estimation process of the parameters for the fitted distribution (Lloyd-Hughes and Saunders 2002, Mishra and Singh 2010). The length of available precipitation record influences the reliability of SPI; the longer the length of record used, the more reliable the SPI values will be (Wu et al. 2005).

In this study, interest is in the appearance and frequency of extremely dry periods when the SPI $\leq-2.00$ (McKee et al. 1995, Edwards 1997). SPI values representative of extremely dry periods were taken from the continuous SPI time series. This procedure generates a new time series that is no longer continuous, but discrete, showing events of extreme drought where the $\mathrm{SPI} \leq-2.00$ and depicting periods of the length $l_{i}$ between extreme drought events. For each order of the SPI, the graphical appearance of extreme drought events can be illustrated with drought indicator diagrams where a vertical line on the time scale represents the drought, and the ap- 
pearance and thickness of the line defines the duration of the extreme drought.

Trends in extreme drought appearance were tested with the nonparametric association measure of Spearman's coefficient $\rho$. Time periods of the length $l_{i}$ between extreme events were listed according to their position $t_{i}$ in the time series and were ranked according to $l_{i}$. Spearman's coefficient $\rho$ (Wilks 1995) is defined as

$$
\rho=1-\frac{6 \sum_{1}^{n} d_{i}^{2}}{n\left(n^{2}-1\right)}
$$

where $n$ is the number of ranks and $d$ is the difference between the rank of $l_{i}$ and its position $t_{i}$ in the time series. The significance of $\rho$ is tested with a null hypothesis $H_{0}: \rho=0$ and an alternative hypothesis $H_{a}: \rho \neq 0 . \rho$ is distributed with the standardised variable $\mathrm{t}$ :

$$
\mathrm{t}=|\rho| \sqrt{\frac{n-2}{1-\rho^{2}}}
$$

according to the student's probability density function (Wilks 1995).

All calculations in the study were performed with Microsoft Excel $2003^{\circledR}$ spreadsheet procedures.

\section{DATA}

Data used for SPI calculations were taken from the HISTALP project data repository (Auer et al. 2007, Böhm et al. 2010), where homogenised monthly time series of precipitation, air temperature, air pressure, and sunshine for the greater Alpine region are available. Details about homogenisation methods, data gap filling, data generation and data gathering are given elsewhere (Auer et al. 2007). The database covers meteorological stations from France in the west, Bosnia and Herzegovina in the southeast, and southern Germany in the north. The length of available time series differs from station to station and from variable to variable. In the vast majority of stations, available data range from 19th century to 2013. The database is regularly maintained, and repository is available at the project's home page (www.zamg.ac.at/histalp/).

In the paper monthly precipitation data from the south-eastern Alps and their southern foothills were analysed with the SPI. Stations used for the analyses are listed in Table 2 and their spatial position is illustrated in Fig. 1. The area is mainly focused on the surroundings of the Julian Alps, the Savinja Alps and Karavanke to better understand water scarcity characteris- 
Table 2

Basic meta data for precipitation stations

\begin{tabular}{|l|l|c|c|c|c|c|c|}
\hline $\begin{array}{c}\text { Precipitation } \\
\text { station }\end{array}$ & Country & $\begin{array}{c}\text { Starting } \\
\text { year }\end{array}$ & $\begin{array}{c}\text { Ending } \\
\text { year }\end{array}$ & $\begin{array}{c}\text { Number } \\
\text { of data }\end{array}$ & $\begin{array}{c}\text { Maximum } \\
{[\mathrm{mm} / \text { month }]}\end{array}$ & $\begin{array}{c}\text { Average } \\
{[\mathrm{mm} / \mathrm{month}]}\end{array}$ & $\begin{array}{c}\text { Median } \\
{[\mathrm{mm} / \mathrm{month}]}\end{array}$ \\
\hline Celje & Slovenia & 1853 & 2008 & 1872 & 342 & 100 & 91.0 \\
Eisenkappel & Austria & 1886 & 2008 & 1477 & 374 & 108 & 99.0 \\
Klagenfurt & Austria & 1813 & 2009 & 2352 & 320 & 81 & 71.5 \\
Kočevje & Slovenia & 1872 & 2008 & 1644 & 468 & 118 & 106.0 \\
Ljubljana & Slovenia & 1853 & 2009 & 1884 & 733 & 123 & 112.0 \\
Maribor & Slovenia & 1876 & 2008 & 1596 & 303 & 89 & 80.0 \\
Trieste & Italy & 1841 & 2007 & 2004 & 370 & 88 & 78.0 \\
Udine & Italy & 1803 & 2007 & 2460 & 616 & 122 & 111.0 \\
Villach & Austria & 1888 & 2008 & 1452 & 367 & 97 & 89.5 \\
\hline
\end{tabular}

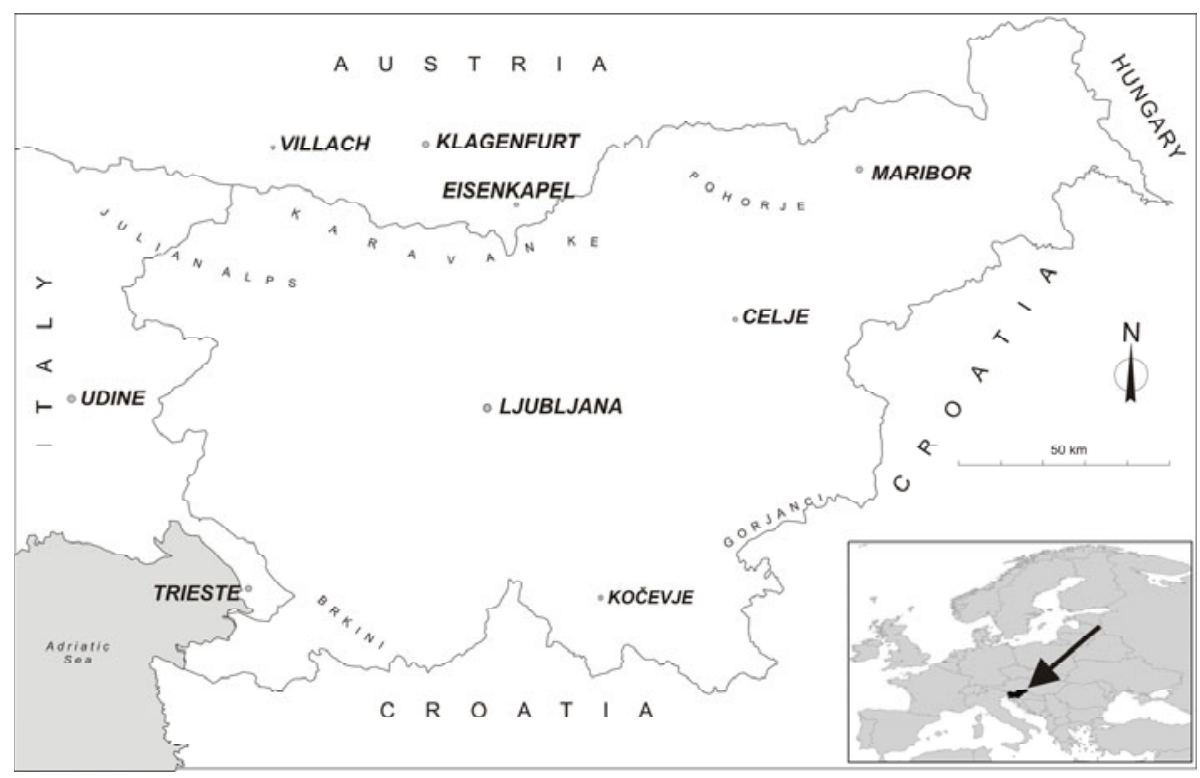

Fig. 1. Position of the HISTALP precipitation stations.

tics in the region. In the analysed data set, only the Eisenkappel station in Austria is positioned inside of a higher mountainous region. Villach and Klagenfurt stations in Austria and Maribor in Slovenia were positioned in the Drava River valley, extending from west to east. Precipitation stations Celje, Ljubljana and Kočevje in Slovenia were positioned inside intermountain basins surrounded by hills and mountains. Precipitation stations Udine and Trieste in Italy were positioned in an area open to the direct influences of the Adriatic Sea from the south. 
The Trieste precipitation station was positioned near the coast, and Udine precipitation station on the flat plain that in the north, extends to the Julian Alps.

Four synoptic scale motions were significant for the area. The first was the Mediterranean cyclogenesis where, in the area of Genoa Bay and the Northern Adriatic, secondary cyclones deepen. The consequences of this process are intensive precipitation and strong southern winds. Among other synoptic scale motions, the expansion of Azorean anticyclones, the expansion of Siberian anticyclones and the passage of cold fronts from Central Europe are present (Pučnik 1980, Rakovec and Vrhovec 2000). In the coastal region, the climate can be classified as Mediterranean; in the north, it changes to sub-Alpine climatic regime and in the mountain region, it is classified as Alpine.

Analyses were performed with two data sets. When only station mode analysis was performed, the entire available data set for the station was used, as available from the HISTALP project home page at the end of 2012 when the database for calculations was formed. For the comparison proposes between all stations, only the period of complete coverage among all stations between 1888 and 2007 was used. In the precipitation time series applied, no data gaps were present. Basic time series metadata and basic descriptive statistics of monthly precipitation data sets are illustrated in Table 2 . At all precipitation stations, several months were without any precipitation; therefore, minimum precipitation amount is not listed in Table 2.

\section{RESULTS AND DISCUSSION}

\subsection{SPI time series}

SPI values for $1,3,6,12,24$, and 48 months usually applied in practical applications were calculated for the HISTALP precipitation stations listed in Table 2. Calculations were performed for the available period and for the comparison proposed between stations from 1888 to 2007, representing a matching period of all stations. As an example, the calculated values are graphically illustrated in Fig. 2 for the precipitation station Udine in Italy with the longest precipitation record in the area. Similar illustrations can be presented for other precipitation stations from Table 2. Comparisons of different SPI order showed the different natures of the obtained time series. Time series with shorter SPI values were more erratic than time series with longer SPI. SPI1 very much resembled a time series with the characteristics of high-frequency random noise; the higher order SPI showed less erratic time series. In higher order SPI, longer periods with less high-frequency noise are becoming more visible and the structure of the time series was more distinctive. 
HISTALP precipitation station Udine - Italy
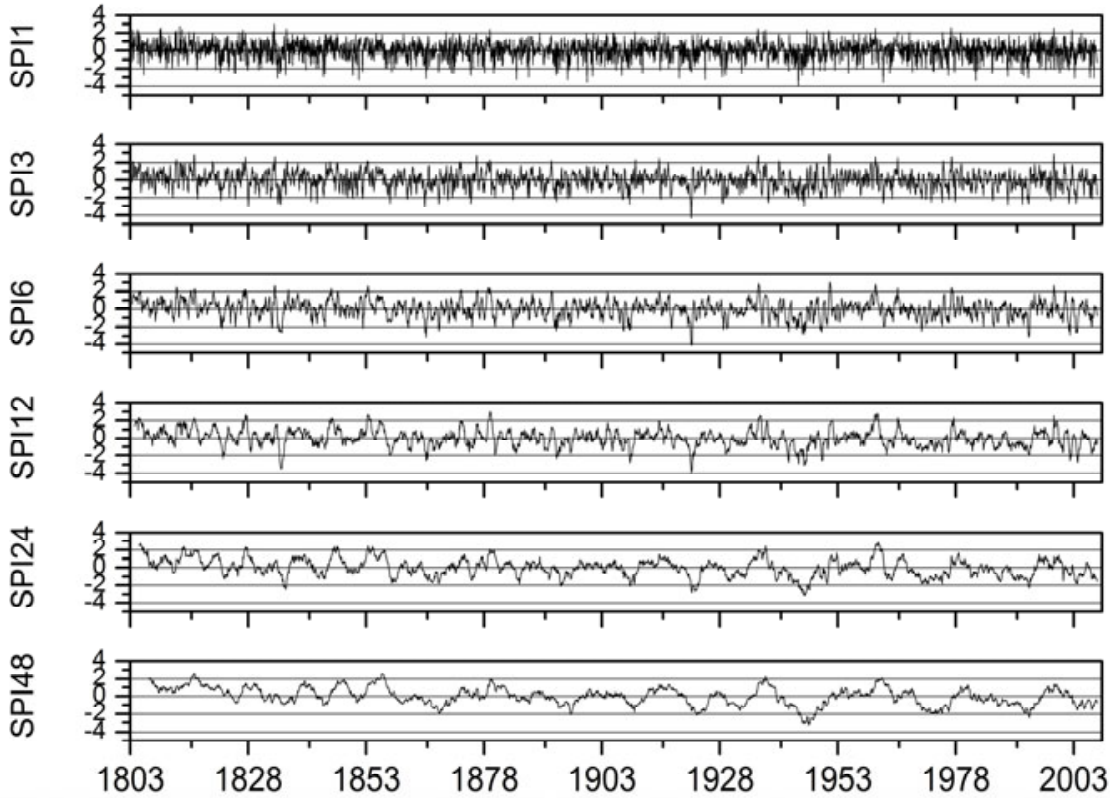

Fig. 2. SPI calculation for HISTALP precipitation station Udine, Italy (period 18132007).

\subsection{Linear trends in SPI time series}

From the graphical representation and numerical values of all SPI variables, negative trends were apparent. In all cases, relatively high SPI values were present at the start of a time series, and smaller values were present at the end of the data period. Based on these observations, station-based linear trends of each $\mathrm{SPI}_{i}$ for the available data period from Table 2 were calculated based on the regression equation

$$
\mathrm{SPI}_{i}=a_{i} t+b_{i}
$$

where $a_{i}$ is the slope of the linear trend, $b_{i}$ is the intercept, and $t$ is the time of observation. Results of regression line slope $a_{i}$ calculations are presented in Table 3.

From the calculated values, it is seen that the highest, most positive, trends were present for lower order $\mathrm{SPI}_{i}$; for higher order $\mathrm{SPI}_{i}$, lower, more negative, trends were present. The trend was systematic, showing, for each station, gradual decreases in trend values from low order $\mathrm{SPI}_{i}$ to high order $\mathrm{SPI}_{i}$. However, trends differed among stations; the highest trends were calculated for Villach, Austria, and lowest for Ljubljana, Slovenia. 
Table 3

Linear trends - slope $a_{i}$ of SPI values for all precipitation stations

\begin{tabular}{|l|c|c|c|c|c|c|}
\hline Precipitation station & SPI1 & SP3 & SPI6 & SPI12 & SPI24 & SPI48 \\
\hline Celje & -0.00003 & -0.00011 & -0.00014 & -0.00019 & -0.00026 & -0.00036 \\
Eisenkappel & -0.00014 & -0.00025 & -0.00035 & -0.00041 & -0.00072 & -0.00097 \\
Klagenfurt & -0.00007 & -0.00014 & -0.00021 & -0.00031 & -0.00045 & -0.00059 \\
Kočevje & -0.00007 & -0.00014 & -0.00022 & -0.00034 & -0.00052 & -0.00077 \\
Ljubljana & -0.00003 & -0.00007 & -0.00008 & -0.00012 & -0.00019 & -0.00022 \\
Maribor & -0.00017 & -0.00035 & -0.00048 & -0.00066 & -0.00093 & -0.00123 \\
Trieste & -0.00008 & -0.00015 & -0.00023 & -0.00033 & -0.00049 & -0.00067 \\
Udine & -0.00011 & -0.00017 & -0.00023 & -0.00031 & -0.00049 & -0.00053 \\
Villach & -0.00015 & -0.00036 & -0.00049 & -0.00069 & -0.00100 & -0.00127 \\
\hline
\end{tabular}

In the comparison between slope $a_{i}$ and $\mathrm{SPI}_{i}$, order systematic relation could be detected. The positive values of linear trends presented in Table 3 were plotted against $\mathrm{SPI}_{i}$ order in a double logarithmic diagram (Fig. 3) which showed a straightforward relation. In this diagram, nearly all observations for the station were distributed along the line that showed a relation which could be described by a power law function.

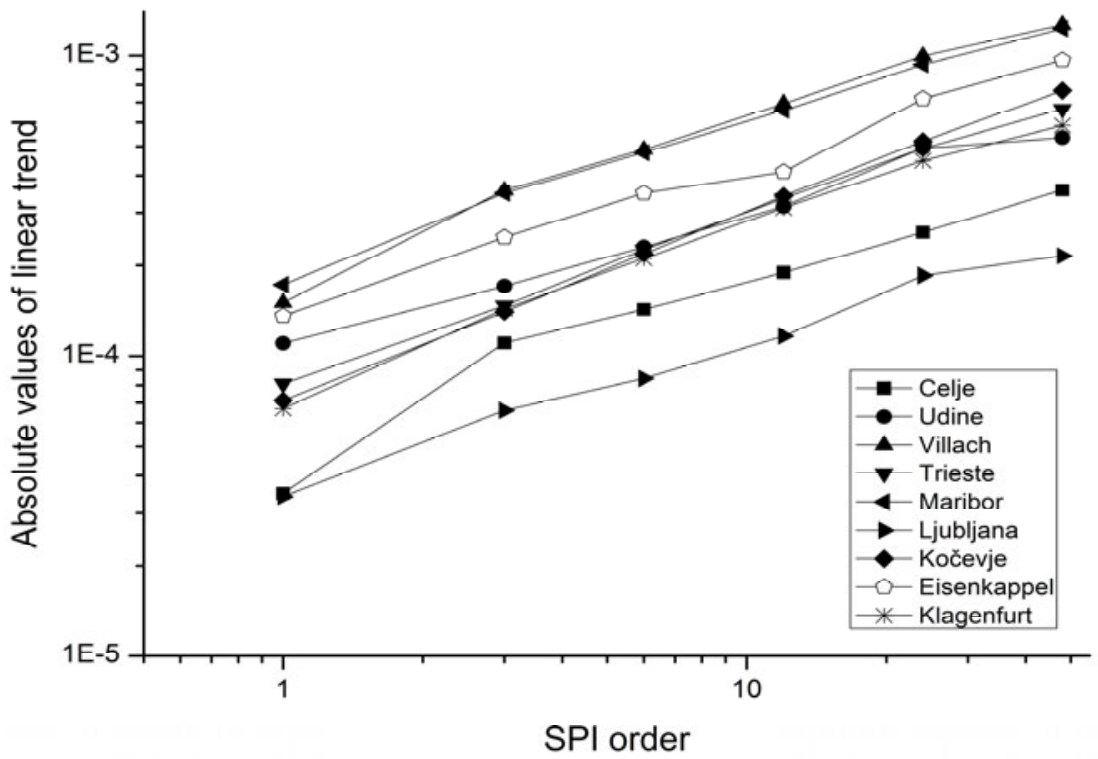

Fig. 3. Relation between positive values of linear trends in SPI time series and SPI order in double logarithmic diagram. 


\section{Table 4}

Power law model parameters for the relation

between time linear trend of SPI and its order

\begin{tabular}{|l|c|c|}
\hline \multirow{2}{*}{ Precipitation station } & \multicolumn{2}{|c|}{ Power model parameters } \\
\cline { 2 - 3 } & $A$ & $B$ \\
\hline Eisenkappel & 0.00014 & 0.50 \\
Celje & 0.00009 & 0.36 \\
Klagenfurt & 0.00007 & 0.56 \\
Kočevje & 0.00007 & 0.62 \\
Ljubljana & 0.00004 & 0.48 \\
Maribor & 0.00019 & 0.50 \\
Trieste & 0.00008 & 0.55 \\
Udine & 0.00011 & 0.43 \\
Villach & 0.00017 & 0.54 \\
\hline
\end{tabular}

The only exception was Celje where SPI1 declined from the overall trend of the rest of the calculated $\mathrm{SPI}_{i}$. The power law model is defined as

$$
a_{i}=A \mathrm{SPI}_{i}^{B}
$$

where $a_{i}$ is the slope of the SPI $\mathrm{Sinear}_{i}$ trend line from above Eq. 8 and $A$ and $B$ are parameters of the power model. Parameters $A$ and $B$ of the model are given in Table 4. Power law parameters $A$ and $B$ for Celje were calculated without SPI1. For all stations, the correlation coefficient was nearly 1 and therefore not listed.

The differences between parameters were not large. The parameter $B$ defining slope in the double logarithmic diagram was distributed in a narrow range, from 0.36 for Celje, and to 0.62 at highest for Kočevje; all other $B$ parameters were very close to each other. Differences between parameters $A$ were also small, and some lines in Fig. 3 were overlapping. Negative linear trends of $\mathrm{SPI}_{i}$ are consistent with the well-know long-term, slow decline of precipitation in the region. Similarities in power law parameters did not only confirm the decline in the long-term precipitation amount, but also showed that declining trends between precipitation stations were relatively similar and that the long-term precipitation regime behaviour was relatively stable with the same properties across the region. Similar stability could be also observed in the relation between inter-drought periods.

\subsection{Inter-drought periods}

To prepare data for Spearman's test, inter-drought lengths $l_{i}$ between extreme events were calculated for each station and each $\operatorname{SPI}_{i}$. Following the 
test, no significant trends were detected, and in all cases, the null hypothesis was accepted. These results illustrated that, in a period of more than $120 \mathrm{ob}-$ servation years, time series of extreme droughts are random.

Because time trends of extreme drought events were randomly distributed, the question was raised if it was possible to model their appearance with the probability model of inter-droughts periods. Data for each particular $\mathrm{SPI}_{i}$ and each precipitation station are illustrated in Table 5.

Table 5

Numbers of periods between the extreme droughts

\begin{tabular}{|l|c|c|c|c|c|c|}
\hline Precipitation station & SPI1 & SP3 & SPI6 & SPI12 & SPI24 & SPI48 \\
\hline Celje & 52 & 31 & 23 & 15 & 10 & 5 \\
Eisenkappel & 45 & 30 & 14 & 16 & 7 & 2 \\
Klagenfurt & 51 & 26 & 21 & 13 & 8 & 7 \\
Kočevje & 47 & 28 & 27 & 14 & 16 & 11 \\
Ljubljana & 75 & 36 & 19 & 16 & 13 & 7 \\
Maribor & 49 & 31 & 26 & 16 & 9 & 6 \\
Trieste & 57 & 27 & 17 & 12 & 11 & 9 \\
Udine & 53 & 31 & 21 & 15 & 10 & 3 \\
Villach & 53 & 28 & 26 & 13 & 10 & 2 \\
\hline
\end{tabular}

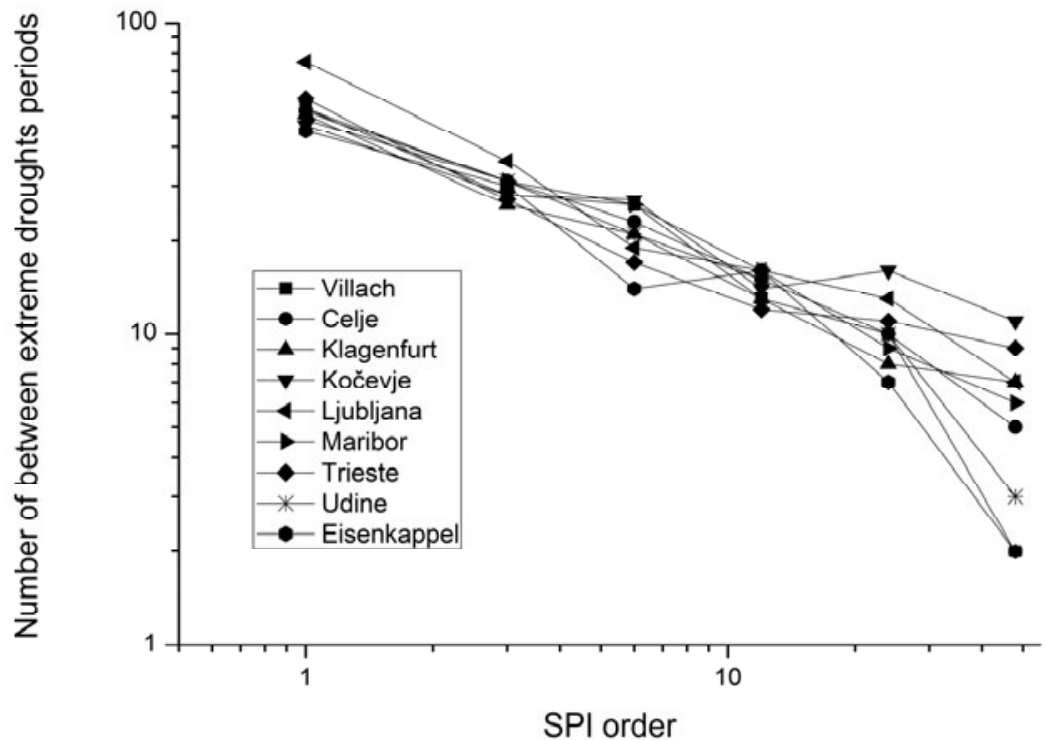

Fig. 4. Number of periods between the extreme droughts. 
Again, data can be illustrated in the double logarithmic diagram (Fig. 4). As in Fig. 2, the relation between variables was apparent and it could be modelled with the power law model defined as:

$$
N=N_{0} \mathrm{SPI}^{C} .
$$

This model implied Pareto distribution as a proper probability function model of the appearance of inter-drought periods in relation to the SPI order. Results of power model parameters, $N_{0}$ and $C$, are shown in Table 6. In Fig. 4, a relatively uniform middle part of the diagram, between SPI3 and SPI24, can be seen. Some discrepancies among the stations are visible at SPI1 and SPI48. To discern the influences of SPI48 on the model parameters, estimation models were calculated twice. The first model was calculated with the entire data set of inter-drought periods, and the second model was calculated without data for SPI48. For all stations, except of Kočevje, Maribor and Ljubljana, the correlation coefficient $r$ of the regression model was higher for the second; however, differences between correlation coefficients were small, thus implying that SPI48 was related to other SPI orders in the same way. Regarding Fig. 4 and the regression parameter calculations in Table 6, the behaviour of the stations in relation to the number interdrought periods was similar. Exceptions to this was Ljubljana, which showed a relatively high $N_{0}$ implying that short-term droughts were more frequent than at other stations, and Kočevje, where parameters $C$ and $N_{0}$ were the lowest.

Table 6

Parameters of power model for numbers of periods

between the extreme droughts in relation to SPI order

\begin{tabular}{|l|c|c|c|c|c|c|}
\hline \multirow{2}{*}{ Precipitation station } & \multicolumn{3}{|c|}{ Whole data set } & \multicolumn{3}{c|}{ Data set without SPI48 } \\
\cline { 2 - 7 } & $C$ & $N_{0}$ & $r$ & $C$ & $N_{0}$ & $r$ \\
\hline Celje & -0.59 & 59 & -0.988 & -0.47 & 59 & -0.997 \\
Eisenkappel & -0.74 & 59 & -0.941 & -0.50 & 52 & -0.954 \\
Klagenfurt & -0.53 & 50 & -0.993 & -0.51 & 57 & -0.994 \\
Kočevje & -0.37 & 45 & -0.961 & -0.33 & 48 & -0.939 \\
Ljubljana & -0.58 & 68 & -0.985 & -0.51 & 73 & -0.975 \\
Maribor & -0.55 & 57 & -0.985 & -0.47 & 59 & -0.978 \\
Trieste & -0.48 & 47 & -0.971 & -0.49 & 56 & -0.979 \\
Udine & -0.68 & 64 & -0.961 & -0.47 & 59 & -0.999 \\
Villach & -0.75 & 70 & -0.932 & -0.48 & 59 & -0.981 \\
\hline
\end{tabular}


The implication of the power model related not only to the matter of the heuristic model fitting the data, but also to the structure and frequency of drought appearance. While it was obvious that the number of shorter droughts is higher than the number of longer droughts, it was not obvious that SPI orders were functionally related. This relation followed from the definition of SPI where values for particular $\mathrm{SPI}_{i}$ orders were summed. The power model showed that the structure of droughts was hierarchical; a larger number of shorter droughts led to the lower number of longer droughts. The modelling of the Pareto distribution showed that the process of drought generation was random, as was also shown with the Spearman coefficient test.

\subsection{Comparison of $\mathrm{SPI}_{i}$}

The time series of different precipitation stations and for $\mathrm{SPI}_{i}$ of different orders were compared for the matching period of data between 1888 and 2007 with Pearson's correlation coefficient. For SPI3 and higher, results are shown in Table 7. All correlation coefficients were significantly higher than 0 and were relatively high. The lowest correlation coefficient $r=0.44$ was found for SPI3, regarding the relation between Kočevje and Villach, where the air distance between the two was around $150 \mathrm{~km}$. However, the Karavanke and Julian Alps lie between those two stations with altitudes more than $2000 \mathrm{~m}$ above sea level. The highest air distance was between precipitation stations Maribor and Udine, around $260 \mathrm{~km}$. In this case, the correlation was also relatively low, but slightly higher than in the former case. Between these two precipitation stations lie the entire Julian Alps and Savinja Alps, as well as their foothills. The highest correlation was detected between Klagenfurt and Villach, where the air distance between precipitation stations was only around $40 \mathrm{~km}$. Both stations were positioned in the same valley, extending from east to west. All the described characteristics of Pearson's correlation coefficient showed that the correlation between the same orders of SPI was very much related to the distance between precipitation stations. Stations that were much closer to each other had higher correlation coefficients than stations that were more distant. Correlation coefficients from Table 7 show that the $\mathrm{SPI}_{i}$ field and its time series are spatially correlated. This was expected, as the correlation structure of a precipitation field was also spatially correlated. The results also showed that the correlation structure, independent of SPI order, was relatively persistent. Correlations between stations were relatively stable; they did not change much among different SPI orders.

\subsection{Time-dependent extreme drought appearance}

The hierarchy of different droughts lengths defined through the $\mathrm{SPI}_{i}$ order was clearly visible from the indicator diagrams. For example, all indicator 
Table 7

Pearson correlation coeffients $r$ between precipitation stations for different SPI orders

\begin{tabular}{|c|c|c|c|c|c|c|c|c|c|}
\hline \begin{tabular}{|c|c} 
SPI3 \\
correlation
\end{tabular} & Vilach & Celje & Klagenfurt & Kočevje & Ljubljana & Maribor & Trieste & Udine & $\begin{array}{c}\text { Eis. } \\
\text { Kappel }\end{array}$ \\
\hline Vilach & 1.00 & & & & & & & & \\
\hline Celje & 0.69 & 1.00 & & & & & & & \\
\hline Klagenfurt & 0.88 & 0.72 & 1.00 & & & & & & \\
\hline Kočevje & 0.60 & 0.74 & 0.63 & 1.00 & & & & & \\
\hline Ljubljana & 0.69 & 0.82 & 0.72 & 0.79 & 1.00 & & & & \\
\hline Maribor & 0.69 & 0.82 & 0.71 & 0.68 & 0.72 & 1.00 & & & \\
\hline Trieste & 0.53 & 0.58 & 0.52 & 0.64 & 0.69 & 0.52 & 1.00 & & \\
\hline Udine & 0.61 & 0.53 & 0.56 & 0.55 & 0.65 & 0.47 & 0.70 & 1.00 & \\
\hline Eis.Kappel & 0.84 & 0.76 & 0.88 & 0.68 & 0.75 & 0.74 & 0.59 & 0.59 & 1.00 \\
\hline \begin{tabular}{|c|c} 
SPI6 \\
correlation
\end{tabular} & Vilach & Celje & Klagenfurt & Kočevje & Ljubljana & Maribor & Trieste & Udine & $\begin{array}{c}\text { Eis. } \\
\text { Kappel }\end{array}$ \\
\hline Vilach & 1.00 & & & & & & & & \\
\hline Celje & 0.55 & 1.00 & & & & & & & \\
\hline Klagenfurt & 0.72 & 0.69 & 1.00 & & & & & & \\
\hline Kočevje & 0.44 & 0.70 & 0.59 & 1.00 & & & & & \\
\hline Ljubljana & 0.55 & 0.81 & 0.68 & 0.79 & 1.00 & & & & \\
\hline Maribor & 0.58 & 0.80 & 0.70 & 0.64 & 0.70 & 1.00 & & & \\
\hline Trieste & 0.46 & 0.56 & 0.51 & 0.63 & 0.68 & 0.51 & 1.00 & & \\
\hline Udine & 0.52 & 0.53 & 0.54 & 0.53 & 0.65 & 0.47 & 0.70 & 1.00 & \\
\hline Eis.Kappel & 0.67 & 0.74 & 0.87 & 0.64 & 0.73 & 0.73 & 0.60 & 0.59 & 1.00 \\
\hline \begin{tabular}{|c|} 
SPI12 \\
correlation
\end{tabular} & Vilach & Celje & Klagenfurt & Kočevje & Ljubljana & Maribor & Trieste & Udine & $\begin{array}{c}\text { Eis. } \\
\text { Kappel }\end{array}$ \\
\hline Vilach & 1.00 & & & & & & & & \\
\hline Celje & 0.66 & 1.00 & & & & & & & \\
\hline Klagenfurt & 0.87 & 0.66 & 1.00 & & & & & & \\
\hline Kočevje & 0.55 & 0.65 & 0.56 & 1.00 & & & & & \\
\hline Ljubljana & 0.64 & 0.80 & 0.64 & 0.79 & 1.00 & & & & \\
\hline Maribor & 0.71 & 0.80 & 0.69 & 0.58 & 0.69 & 1.00 & & & \\
\hline Trieste & 0.55 & 0.52 & 0.50 & 0.61 & 0.67 & 0.50 & 1.00 & & \\
\hline Udine & 0.59 & 0.52 & 0.50 & 0.52 & 0.67 & 0.48 & 0.68 & 1.00 & \\
\hline Eis.Kappel & 0.81 & 0.72 & 0.85 & 0.61 & 0.69 & 0.72 & 0.60 & 0.58 & 1.00 \\
\hline
\end{tabular}


Table 7 (continuation)

\begin{tabular}{|l|c|c|c|c|c|c|c|c|c|}
\hline $\begin{array}{c}\text { SPI24 } \\
\text { correlation }\end{array}$ & Vilach & Celje & Klagenfurt & Kočevje & Ljubljana & Maribor & Trieste & Udine & $\begin{array}{c}\text { Eis. } \\
\text { Kappel }\end{array}$ \\
\hline Vilach & 1.00 & & & & & & & & \\
Celje & 0.65 & 1.00 & & & & & & & \\
Klagenfurt & 0.87 & 0.64 & 1.00 & & & & & & \\
Kočevje & 0.59 & 0.66 & 0.59 & 1.00 & & & & & \\
Ljubljana & 0.61 & 0.81 & 0.61 & 0.80 & 1.00 & & & & \\
Maribor & 0.70 & 0.80 & 0.65 & 0.57 & 0.70 & 1.00 & & & \\
Trieste & 0.53 & 0.48 & 0.46 & 0.60 & 0.62 & 0.49 & 1.00 & & \\
Udine & 0.55 & 0.51 & 0.45 & 0.58 & 0.69 & 0.49 & 0.66 & 1.00 & \\
Eis.Kappel & 0.80 & 0.71 & 0.84 & 0.67 & 0.71 & 0.69 & 0.61 & 0.58 & 1.00 \\
\hline \multicolumn{1}{|c|}{ SPI48 } & Vilach & Celje & Klagenfurt & Kočevje & Ljubljana & Maribor & Trieste & Udine & Eis. \\
correlation & 1.00 & & & & & & & & \\
\hline Vilach & 1.00 appl \\
Celje & 0.69 & 1.00 & & & & & & & \\
Klagenfurt & 0.91 & 0.63 & 1.00 & & & & & & \\
Kočevje & 0.66 & 0.69 & 0.65 & 1.00 & & & & & \\
Ljubljana & 0.63 & 0.79 & 0.63 & 0.83 & 1.00 & & & & \\
Maribor & 0.72 & 0.81 & 0.65 & 0.60 & 0.67 & 1.00 & & & \\
Trieste & 0.56 & 0.48 & 0.51 & 0.63 & 0.63 & 0.49 & 1.00 & & \\
Udine & 0.54 & 0.56 & 0.48 & 0.66 & 0.75 & 0.51 & 0.70 & 1.00 & \\
Eis.Kappel & 0.86 & 0.72 & 0.87 & 0.75 & 0.74 & 0.69 & 0.66 & 0.62 & 1.00 \\
\hline
\end{tabular}

Extreme drought appearance - HISTALP station Ljubljana
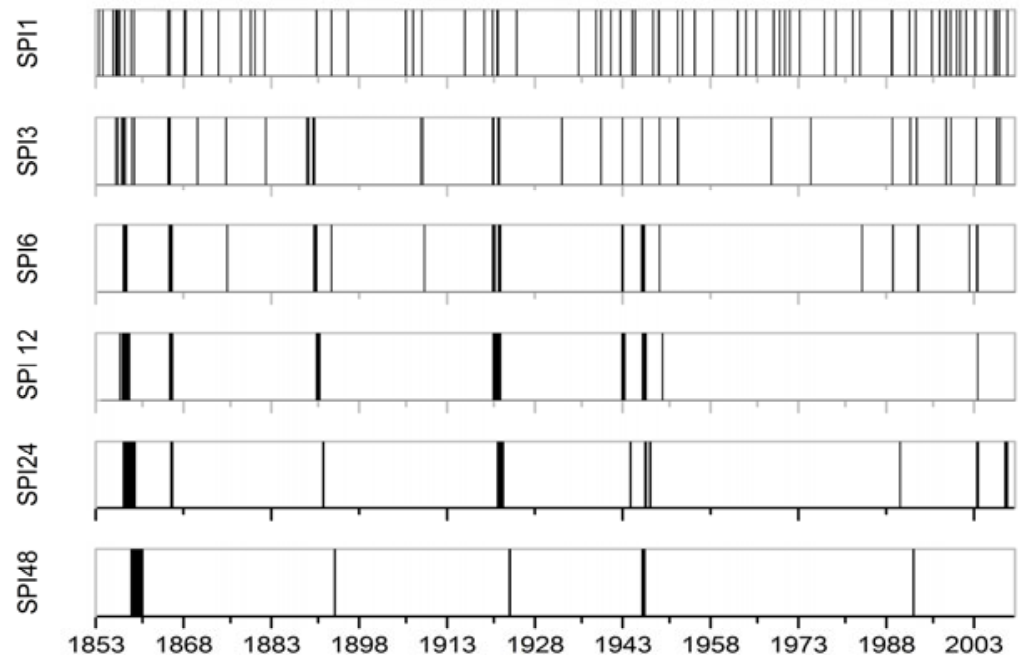

Fig. 5. Indicator diagrams for Ljubljana station. 
diagrams for Ljubljana are represented in Fig. 5. As depicted in the power law models, this hierarchy structure was not only expected from a stationbased point of view, but also in the comparison of drought indications between precipitation stations. Comparisons between all sets of indicator diagrams of SPI for its particular order are shown in Fig. 6. Indicator diagrams were presented for the data matching the period between 1888 and 2007. For a clearer presentation of the graphs, the southernmost station (Kočevje) was not included in the illustration.

SPI1
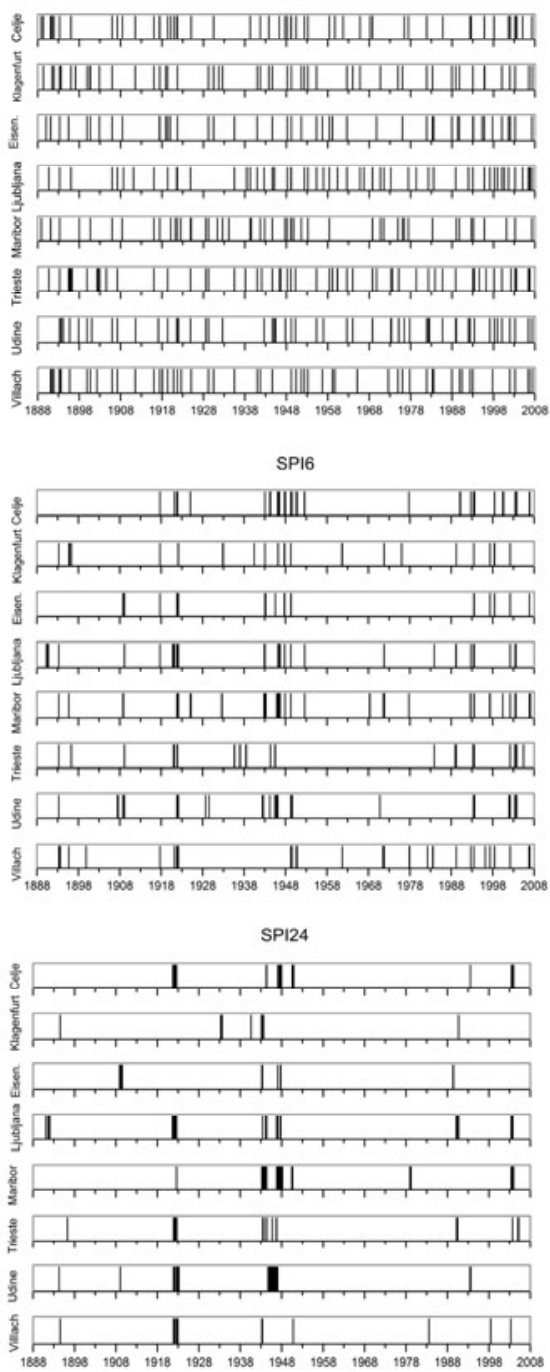
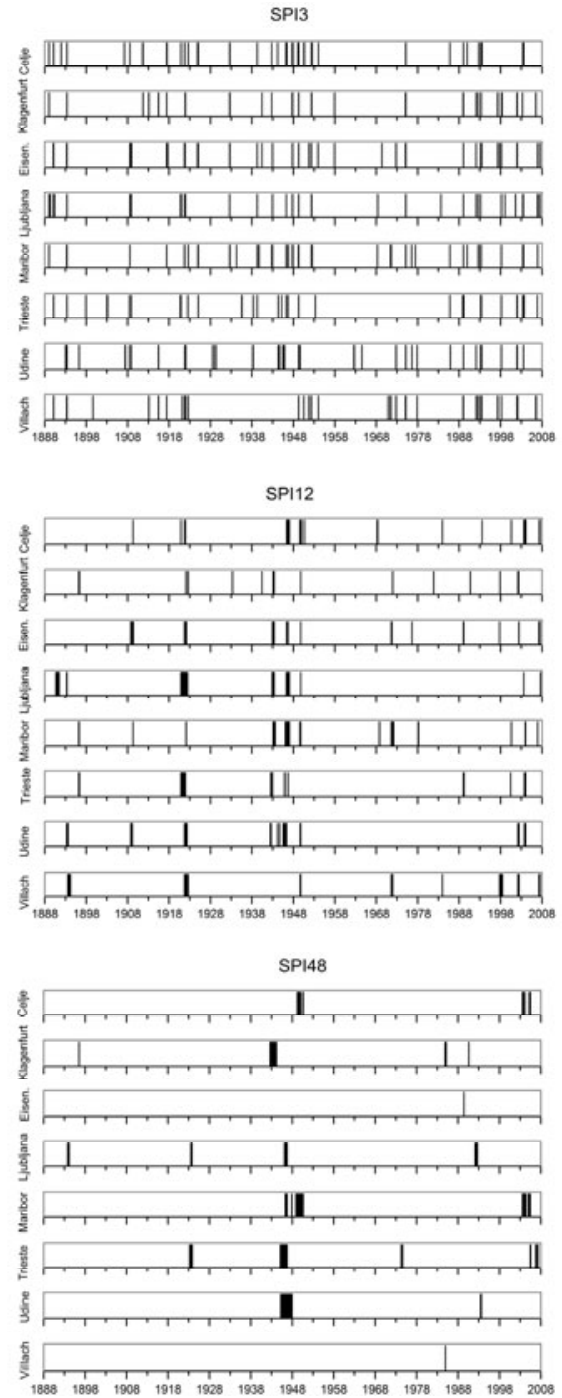

Fig. 6. Comparison of indicator diagrams between stations for different SPI orders. 
The comparison between SPI1 showed no clear pattern; it was also difficult to discern any time-dependent trends. Time patterns of extreme droughts emerged with values higher than SPI3. Starting from SPI6, the division of the diagrams into the earlier two thirds and later third could be seen, separating each part at approximately 1968. Before that year, extreme droughts were hierarchically grouped, they were mostly related to similar periods and were on a vertical scale (i.e., at the same time period), showing very similar patterns. After 1968, droughts were more scattered in time, showing less of a pattern than before. In the time period before 1968 drought propagation mechanism can be interpreted as more uniform with similar characteristics between stations. After 1968 the characteristics of drought propagation probably changed, making the area less homogeneous; differences between extreme droughts were more random than before.

In the following paragraphs, extreme drought time appearance was analysed. The analysis of extreme drought appearance rested mainly on SPI48. Other lower order $\mathrm{SPI}_{i}$ are too frequent too be listed as a whole. For their representation, a graphical illustration was more useful.

In the matching period for all precipitation stations presented in the diagram from 1888 to 2007 (Fig. 6), the first drought crisis appeared in the period between 1888 and 1896. Extreme drought periods of SPI48 were detected only at Ljubljana and Udine; however, at lower SPI orders, this drought crisis was clearly visible (Fig. 6). The next profound drought crisis was detected after World War I. Extremes detected by SPI48 started at Kočevje on October 1921 and ended (also in Kočevje) on January 1924; during this period, SPI48 droughts were detected at Trieste, Udine and Ljubljana. At other stations, this drought event was not detected by SPI48, but was clearly visible through lower order SPI (Fig. 6).

An extreme drought crisis was detected in the period during World War II and ended shortly after. This period was visible in all diagrams higher than SPI6 (Fig. 6). The first signs of extreme droughts detected with SPI6 appeared at Udine in June 1942; shortly after that, a SPI6 extreme drought was detected at all other precipitation stations. This crisis then extended to SPI12, SPI24, and SPI48. The long-term drought crisis defined by SPI48 during this period was detected at all stations except of Eissenkapel and Villach, which were positioned north of the Karavanke Mountains and were influenced by the Alpine climatic regime of Central Europe. During World War II, the extreme drought detected with SPI48 first appeared in Klagenfurt between August 1942 and July 1943. Then it reappeared at this station in October 1943, and then again between December 1943 and April 1944; with short interruptions, this extreme drought lasted from August 1942 and April 1944. This crisis was than experienced at the Udine precipitation station; it began in September 1944, then it reappeared in February 1945 and lasted until April 
1948. At other stations, the extreme drought crisis of the mid-20th century lasted until after the World War II. In Trieste, extreme drought started in February 1945 and lasted until October 1946. In Ljubljana an extreme SPI48 drought lasted from April 1946 and October 1946. In Celje, the drought started in April 1949 and ended in December 1949. For Kočevje and Maribor this extreme drought crisis had several intervals and was (among analysed precipitation stations) the most profound. In Kočevje, the extreme drought started in July 1946 and ended on October 1946, then reappeared in November 1947 and then again in March and April 1948. Maribor suffered the largest number of SPI48 extreme drought periods after World War II. The drought crisis started in April 1946 and lasted until October 1946, then from November to December 1947, and finally from November 1948 to August 1950. In total, at the Maribor precipitation station the drought crisis lasted from April 1946 to August 1950 (52 months).

After 1968, where changes in the drought pattern can be detected from Fig. 6, the first extreme SPI48 drought appeared in Udine in November 1972 and then in Kočevje in August 1973 and then at the same stations again between March and August 1974. An extreme SPI48 drought in 1974, between March and August, was also detected in Trieste. The next extreme drought was detected in 1984 and 1985 between months November and February in Klagenfurt. In the decade between 1980 and 1990, an extreme drought crisis was detected only on the northern side of the Karavanke Mountains. An extreme SPI48 drought was in Villach, and was detected in December 1984 and June 1989 in Eisenkappel. For the latter two stations, these are the only extreme SPI48 drought events of detected after 1968. There were more SPI48 drought crises detected in the last decade of the 20th century. In year 1990, droughts were detected between June and August in Klagenfurt and between June and September in Kočevje. In 1992, a crisis was detected in Ljubljana in August and September and in Kočevje in February, March, and September. In 1993, an SPI48 extreme drought was detected only in Udine between May and September. In the second half of the last decade, no extreme SPI48 droughts were detected. The next long drought crisis appeared in 2003; in Europe, this is a very well-known drought crisis (Sušnik et al. 2010). This SPI48 crisis was detected only in Celje and Maribor. The lower order $\mathrm{SPI}_{i}$ detected this crisis at other stations. In 2005 an extreme SPI48 drought was detected in Maribor, Celje, and Trieste. Between October 2006 and April 2007, and again in December 2007, a drought was detected in Trieste. In Maribor in 2008, the drought crisis was detected between June and December.

Extreme drought events, which are not shown in Fig. 6, were detected also before 1888. The earliest extreme long-term SPI48 drought detected was at Klagenfurt precipitation station between August 1835 and February 1836, 
which was followed by another event between May and June 1836, and August and December 1837. From this, it followed that, in the region around Klagenfurt, an extreme drought period reflected by various $\mathrm{SPI}_{i}$ orders lasted for 28 months, from August 1835 to December 1837. Later, an extreme SPI48 drought was detected in Klagenfurt, in the middle of the 20th century. The next long-term SPI48 drought event was detected in the time series of Celje, between July 1857 and January 1860, which was also detected by the Ljubljana precipitation station from January 1859 to January 1860 . The next extreme SPI48 drought was detected in June 1868 in Udine.

\subsection{Extreme drought characteristics in the south-eastern Alps region}

From 1888 until 2007, two different extreme drought regimes could be detected form SPI values and their diagrams. These two periods were somehow artificially divided by the year 1968. Before that period in the region several drought crises that were mostly concomitant could be detected. The periods are as follows: first between 1888 and 1893, second between 1920 and 1923, and third between 1942 and 1950. There were indications that extreme drought patterns appeared also before 1888 , but a scarcity of data did not allow a clear interpretation of extreme drought appearances in the region. After 1968 extreme drought periods appeared to be more irregular, and the correlation between different precipitation stations was not as apparent as before this period. The largest extreme drought periods were detected during World War II and after.

The extreme drought crisis between World War II and the five following years needs special attention that goes beyond timeframe of this study. It was a very special drought crisis, which could be defined as the "World War II extreme drought crisis". It was the longest drought crisis detected from the data of HISTALP database; it was long and clearly visible from all indicator diagrams. However, it did not begin and end at the same time at all stations. This extreme drought propagated in space and time and affected profoundly mainly lower altitude areas; SPI48 was not detected at the Villach and Eisenkappel stations. War periods and times after them are very demanding for meteorological data collection. Data are very often missing, or whole records are lost. Sometimes, the quality of data can also be questioned; data collection procedures were not as strict as they are during peaceful times. Therefore, whether the "World War II extreme drought crisis" was artificially induced by the quality of precipitation measures, was actual extreme natural phenomenon, or a combination of both, remains to be investigated yet. Further, a similar, but not as profound precipitation drought crisis, was observed after World War I.

Indicator diagrams showed a grouping of extreme drought events. In comparison with different SPI orders, the hierarchy of extreme drought 
events was clearly visible. This hierarchy was also related to the power model and Pareto distributions, which showed a relation between the number of inter-droughts periods and the order of SPI. Some of the higher numbers of short-term extreme drought events evolved into a smaller number of longterm extreme drought events. In all drought crises prior to 1968 , such a hierarchy could be detected; however, after that year, the hierarchy of various drought events was no longer clearly defined.

\section{CONCLUSIONS}

Accomplished calculations and interpretations of SPI of various orders from the south-eastern region of the Alps (with an emphasis on Slovenia) require further investigation regarding the precipitation time series and SPI calculation procedures. In the study, gamma distribution was applied as a background probability density function; however, evaluation with other probability density models is needed because there were some indications in the present application that for some of the stations the chosen probability model has not been satisfying.

In the precipitation data sets and in derived $\mathrm{SPI}_{\mathrm{i}}$ time series, strong time trends were observed. It was shown that certain functional relations existed between trends and SPI orders. However, their existence showed that precipitation time series were not stationary. SPI calculation requires a stationary time series. Therefore, further investigation on trend influences on extreme drought detection is needed to estimate if detrending procedures are required.

Along with these questions, adequate definitions of drought threshold values for long time series of precipitation are needed. Trends in precipitation time series influence parameters of the modelling background probability distribution and, therefore, detected intensity of a drought at different parts of the investigated period. In the present study, threshold values for extreme droughts according to McKee et al. $(1993,1995)$ were taken, but these effects were not investigated. The effects of the time series length and their trend on drought intensity detection at different periods must be further investigated from a theoretical point of view as well for the HISTALP data series for the better understanding of drought appearance in the south-eastern Alps region.

Data used for SPI calculations were retrieved from database where data were heavily homogenised with the HOCLIS-system (Auer et al. 2007), rising a question regarding how homogenisation procedures influence SPI calculations. For some of the precipitation stations, data sets based on other homogenisation procedures are available, and SPI calculations based on these datasets must be performed to observe stability of different SPI order. 
Further, an investigation is needed also on the regional correlation structure of SPI fields of different orders.

Several of the detected extreme droughts appeared during winter months. SPI values are not sensitive to the precipitation type; however, consequences of droughts during winter months are different than are droughts during summer months. It will be necessary to compare the share of droughts related to the winter months when snow precipitation is present to the months when only liquid precipitation falls.

The present results of past extreme droughts detected with SPI must be compared to historical data from the catalogues of droughts. Unfortunately, for the investigated area, data are uncompleted and insufficient. Further investigation in this direction is urgently needed.

Acknowledgments. For the data preparation and help during calculations, the author wishes to thank Jure Hictaler and Anja Torkar. Calculations and data reductions were performed during the Alp Water Scarcity project financed under the Alpine Space Program of European Union. The paper was prepared through the research programme "Groundwater and Geochemistry" (P1-0020) of the Geological Survey of Slovenia and was financially supported by the Agency for Research of Republic of Slovenia.

\section{References}

Abramowitz, M., and I. Stegun (eds.) (1972), Handbook of Mathematical Functions with Formulas, Graphs, and Mathematical Tables, Dover Publ., New York.

Auer, I., R. Bohm, A. Jurkovic, W. Lipa, A. Orlik, R. Potzmann, W. Schoner, M. Ungersbock, C. Matulla, K. Briffa, P. Jones, D. Efthymiadis, M. Brunetti, T. Nanni, M. Maugeri, L. Mercalli, O. Mestre, J. M. Moisselin, M. Begert, G. Muller-Westermeier, V. Kveton, O. Bochnicek, P. Stastny, M. Lapin, S. Szalai, T. Szentimrey, T. Cegnar, M. Dolinar, M. GajicCapka, K. Zaninovic, Z. Majstorovic, and E. Nieplova (2007), HISTALP historical instrumental climatological surface time series of the Greater Alpine Region, Int. J. Climatol. 27, 1, 17-46, DOI: 10.1002/joc.1377.

Bobée, B., and F. Ashkar (1991), The Gamma Family and Derived Distributions Applied in Hydrology, Water Resources Publications, Littleton.

Böhm, R., P.D. Jones, J. Hiebl, D. Frank, M. Brunetti, and M. Maugeri (2010), The early instrumental warm-bias: a solution for long central European temperature series 1760-2007, Climate Change 101, 1-2, 41-67, DOI: 10.1007/ s10584-009-9649-4.

Brázdil, R., M. Trnka, P. Dobrovolný, K. Chromá, P. Hlavinka, and Z. Žalud (2009), Variability of droughts in the Czech Republic, 1881-2006, Theor. Appl. Climatol. 97, 3-4, 297-315, DOI: 10.1007/s00704-008-0065-x. 
Briffa, K.R., G. van der Schrier, and P.D. Jones (2009), Wet and dry summers in Europe since 1750: evidence of increasing drought, Int. J. Climatol. 29, 13, 1894-1905, DOI: 10.1002/joc.1836.

Dracup, J.A., K.S. Lee, and E.G. Paulson (1980), On the definition of droughts, $W a-$ ter Resour. Res. 16, 2, 297-302, DOI: 10.1029/WR016i002p00297.

Edwards, D.C. (1997), Characteristics of 20th century drought in the United States at multiple time scales, M.Sc. Thesis, Department of Atmospheric Science, Colorado State University, Fort Collins, USA.

Gocic, M., and S. Trajkovic (2014), Spatiotemporal characteristics of drought in Serbia, J. Hydrol. 510, 110-123, DOI: 10.1016/j.jhydrol.2013.12.030.

Guttman, N.B. (1998), Comparing the Palmer drought index and the standardizet precipitation index, J. Am. Water Resour. Assoc. 34, 1, 113-121, DOI: 10.1111/j.1752-1688.1998.tb05964.x.

Guttman, N.B. (1999), Acepting the standardized precipitation index: A calculation algorithm, J. Am. Water Resour. Assoc. 35, 2, 311-322, DOI: 10.1111/j.1752-1688.1999.tb03592.x.

Hannaford, J., N. Lloyd-Hughes, C. Keef, S. Parry, and C. Prudhomme (2011), Examing the large-scale spatial coherence of European drought using regional indicators of precipitation and steramflow deficit, Hydrol. Process. 25, 7, 1146-1162, DOI: 10.1002/hyp.7725.

Keyantash, J., and J.A. Dracup (2002), The quantification of drought: an evaluation of drought indices, Bull. Am. Meteorol. Soc. 83, 8, 1167-1180.

Kim, D.W., H.R. Byun, K.S. Choi, and S.B. Oh (2011), A spatiotemporal analysis of historical droughts in Korea, J. Appl. Meteorol. Climatol. 50, 9, 1895-1912, DOI: 10.1175/2011JAMC2664.1.

Kingston, D.G., J.H. Stagge, L.M. Tallaksen, and D.M. Hannah (2015), Europeanscale drought: Understanding connection between atmospheric circulation and meteorological drough indices, J. Climate 28, 2, 505-516, DOI: 10.1175/JCLI-D-14-00001.1.

Lloyd-Hughes, B., and M.A. Saunders (2002), A drought climatology for Europe, Int. J. Climatol. 22, 13, 1571-1592, DOI: 10.1002/joc.846.

McKee, T.B., N.J. Doesken, and J. Kleist (1993), The relationship of drought frequency and duration to time scales. In: Proc. Eight Conference on Applied Climatology, Anaheim, California, USA.

McKee, T.B., N.J. Doesken, and J. Kleist (1995), Drought monitoring with multiple time scales. In: Proc. 9th AMS Conference on Applied Climatology, Dallas, USA, American Meteorological Society.

Mishra, A.K., and V.P. Singh (2010), A review of drought concepts, J. Hydrol. 391, 1-2, 204-216, DOI: 10.1016/j.jhydrol.2010.07.012.

Pučnik, J. (1980), Velika Knjiga o Vremenu, Cankarjeva Založba, Ljubljana (in Slovenian). 
Quiring, S.M. (2009), Monitoring drought: An evaluation of meteorological drought indices, Geography Compass 3, 1, 64-88, DOI: 10.1111/j.1749-8198.2008. 00207.x.

Rakovec, J., and T. Vrhovec (2000), Osnove meteorologije za naravoslovce in tehnike, Društvo Matematikov, Fizikov in Astronomov Slovenije, Ljubljana (in Slovenian).

Sheffield, J., and E.F. Wood (2011), Drought - Past Problems and Future Scenarios, Earthscan, London.

Sousa, P.M., R.M. Trigo, P. Aizpurua, R. Nieto, L. Gimeno, and R. Garcia-Herrera (2011), Trends and extremes of drought indices throuhout the 20th century in the Mediterranean, Nat. Hazards Earth Syst. Sci. 11, 1, 33-51, DOI: 10.5194/nhess-11-33-2011.

Spraggs, G., L. Peaver, P. Jones, and P. Ede (2015), Re-construction of historic drought in the Anglian Region (UK) over the period 1798-2010 and the implications for water resources and drought management, J. Hydrol. 526, 231-252, DOI: 10.1016/j.jhydrol.2015.01.015.

Sušnik, A., T. Pogačar, G. Gregorič, J. Roškar, and A. Ceglar (2010), Establishment of agricultural drought monitoring at different spatial scales in southeastern Europe, Acta Agricult. Slov. 95, 3, 231-243, DOI: 10.2478/v10014-0100015-z.

Svoboda, M., D. LeComte, M. Hayes, R. Heim, K. Gleason, J. Angel, B. Rippey, R. Tinker, M. Palecki, D. Stooksbury, D. Miskus, and S. Stephens (2002), The Drought Monitor, Bull. Am. Meteorol. Soc. 83, 8, 1181-1190, DOI: 10.1175/1520-0477(2002)083<1181\%3ATDM>2.3.CO\%3B2.

Wilhite, D.A., and M.H. Glantz (1985), Understanding the drought phenomenon: The role of definitions, Water Int. 10, 111-120, DOI: 10.1080/ 02508068508686328 .

Wilks, D.S. (1995), Statistical Methods in the Atmospheric Sciences, Academic Press, San Diego.

WMO (2006), Drought monitoring and early warning: Concepts, progress and future challenges, World Meteorological Organization Rep. WMO-1006, 24 pp. available from: http://www.wamis.org/agm/pubs/brochures/WMO1006e. pdf.

Wu, H., M.J. Hayes, A. Weiss, and Q. Hu (2001), An evaluation of the standardized precipitation index, the China-Z index and the statistical Z-score, Int. J. Climatol. 21, 6, 745-758, DOI: 10.1002/joc.658.

Wu, H., M.J. Hayes, D.A. Wilhite, and M.D. Svoboda (2005), The effect of the lenght of record on the standardized precipitation index calculation, Int. J. Climatol. 25, 4, 505-520, DOI: 10.1002/joc.1142. 